\title{
Precarious Labor in COVID Times: The Case of Musicians
}

\author{
David Arditi
}

\section{Introduction}

While the coronavirus pandemic continues to wreak havoc on employment opportunities throughout the world, workers who earn a living through precarious employment activities have faced unique barriers to securing wages. The "gig economy" that professed to provide workers with flexibility and fast cash (Ravenelle 2019; Schor 2020) suddenly left these independent contractors without work and without income. When many governments around the world shut down all gatherings of 10 or more people in 2020, the impact was devastating on musicians' lives and many supporting workers in the entertainment industry. The structural insecurity of gig work was amplified as music venues were forced to cancel performances for a year or more. “The 'gig' in the term 'gig economy' refers back to the short-term arrangements typical of a musical event. An aspiring musician might celebrate getting a gig, or tell a friend that they have got a gig in the back room of a pub. This is of course no guarantee that they will get to perform regularly" (Woodcock and Graham 2020:3). Musicians' livelihoods have been exacerbated by their lack of employment contracts and requisite employment protections during the pandemic.

The impact of the pandemic shutdown devastated the live music industry. According to Billboard, between November 1, 2019 and October 31, 2020 ticket sales "fell by $\$ 5$ billion, down to $\$ 1.7$ billion in sales from $\$ 6.7$ billion" the year before (Brooks 2020:101). Note here that the COVID closure of music venues only covers about half of the year reported, but the closure occurred during the most important part of the year for gigging musicians: the summer touring season. However, the $\$ 5$ billion loss of revenue in ticket sales is just the surface. First, "Billboard estimates, the concert industry generates about $\$ 25$ billion, with about $68 \%$ of that generated in the second half of the year" including merchandise, concessions, fees, etc. (Brooks 2020:101). Second, the estimate here is only for the major venues of all sizes that report information to Billboard. This figure does not come close to estimating lost revenue and income for musicians playing at bars, restaurants, parties, and other events across the world. When Billboard tries to estimate lost jobs by claiming "the shutdowns eliminated 75,000-100,000 full-time jobs in live music, and over 12 million positions were affected or eliminated in the events business as a whole" (Brooks 2020:101).1 The problem is the main reported numbers include big music promoters like Live Nation, but not small businesses that book their own talent. While their data are staggering, I do not think a data model exists that can truly estimate the impact on musicians because of the precarious nature of musician employment.

In this paper I argue the COVID-19 pandemic devastated musicians because their precarious labor position made it difficult for them to earn a living without live performances. The current phase of capitalism relies on precarious labor to produce large quantities of cultural goods and experiences while neglecting the living conditions of workers. While most musicians suffered from their precarity, superstar musicians, corporations and businesses found ways to turn the crisis into an opportunity. The COVID-19 pandemic accentuated disparities baked into the current phase of capitalism. To examine the problem, I deploy immanent critique to consider the impact COVID induced shutdown 
has had on musicians. Robert Antonio uses immanent critique "as a means to detecting societal contradictions which offer the most determinate possibilities for emancipatory change" (Antonio 1981:332). While famous musicians sit in an admired position in American society, the reality is most musicians depend on steady gigging to meet their basic and social needs. By highlighting musicians' precarious labor, I demonstrate the way instability characterizes their employment opportunities. While the pandemic shutdown crushed opportunity for most musicians, the top stars continued to use their celebrity status to continue generating income. The contradiction between those with the ability to continue generating income by deploying their stardom and those unable to because of their obscurity builds inequity.

While workers across sectors experienced the effects of being precariously employed, interruptions in the entertainment industries devastated cultural workers. In turn the hardships experienced by musicians is a product of hundreds of years of precariousness musicians have experienced in the capitalist economy.

In this paper, I explore the impact the COVID music closures had on gigging musicians. How did the closure of the live music industry amplify the precariousness of musicians' working situations? First, I develop a theory of the current mode of capitalism. Second, I discuss musicians as precarious ("gig") workers by exploring the way record contracts establish inequity in the recording industry. Finally, I argue the COVID crisis for musicians was largely an effect of their precarious employment situation.

\section{Capitalism Now}

Capitalism is the endless accumulation of capital achieved by two means: 1) increased consumption and 2) exploitation of labor. Capitalism has passed through a series of phases. In each phase, the organization of the social relations of production shifts without fundamentally changing. In other words, capitalism remains the economic system in which workers sell their labor for access to the means of production (owned by capital) in return for a wage. However, the types of jobs, their pay, and the relations of the commodities produced keep changing. The current phase, which I describe here, helps to explain why the COVID-19 pandemic inflicted so much pain on musicians and other workers in the cultural and service industries from their proximity to consumers. In the current moment, capitalism depends on precarious workers and unending consumption.

While musicians have long been subjected to gig work throughout capitalism, the 1970s marked a moment when more labor became subsumed by precarious work as industrial labor retreated and capital began to emphasize "flexible" labor. Beginning in the early 1970s, it became clear that new production systems would increase the production of commodities by a large unionized working class (Braverman 1998). This working class, itself a product of the American war effort in World War II, saw gains in productivity and standards of living. At the time, the productive and consumptive capacity of the working class seemed limitless. This was a product as much of the Fordist phase of capitalism that emphasized paying an amount to workers that enabled them to purchase the products they made. If Ford workers earned enough to buy cars, then Ford would sell more cars. But the logic faded in the 1970s as wage stagnation and inflation slowed the consumptive processes. Capitalists blamed unions and workers as corporations demanded "flexible" labor unencumbered by unions (Gottfried 1995). Then unions and corporations made a bargain for workers to make sacrifices (ex. giving up pensions and wage increases) in return for a reduction in layoffs.

At the same time, capitalism came to operate on increased consumption. Michel Aglietta argued that the emphasis of capitalism shifted from expanding the means of production to the means of consumption (Aglietta 2001). Rather than a capitalism that emphasized producing more of the same commodities and expanding the market, capitalism shifted to allow the same consumers to buy more commodities. For example, the production of phonograph record players would only go so far. Once every household with the financial means to purchase a phonograph owned a phonograph, they no longer had a reason to purchase a new one. Instead, the emphasis came to be selling records to play on the phonograph. Later, there was a correlative planned obsolescence of the phonograph to encourage consumers to replace their old players. Paul Smith contends the increase in "activity-commodities (such as travel, tourism, and sports) and the massive expansion in the catchment of the electronic and print media ... constitute just 
one component in capital's response to the crises of the postwar period" (Smith 1997:48). The expansion of the means of consumption hinges on giving a smaller group of consumers more goods or activities to consume.

Ben Agger introduced the term "fast capitalism" as a way to address the expansion of media texts under a new phase of capitalism (Agger 1988). The speed of production characterized fast capitalism as cultural producers produced more texts than any person could consume. This accelerated production created a ubiquity of cultural texts that does not allow people to read, watch or consume them nonetheless think about them. In the Frankfurt School tradition, Agger views reason and critical thinking as a key element to overcoming domination, but the rate of production does not permit the careful reading and contemplation of these texts. This phase of capitalism expanded the means of consumption beyond the point where consumers could read, watch, or consume the texts they purchased. People would buy books they would never read or buy VHS tapes of movies they would never watch. When they would read or watch these books or movies, they would move on to the next without much thought and certainly without discussing the texts with others. The expansion of the means of consumption accelerated the production of cultural texts at a time when workers most needed to come together in solidarity to resist the corporate changes to labor safety nets. Since the system demands more goods, people see a constant opportunity to work. However, more people working in a particular area stifles wages.

In Blog Theory (Dean 2013), Jodi Dean sees a sped up capitalism similar to Ben Agger (2004). Dean contends "the temporal take-over of theory displaces sustained critical thought, replacing it with the sense that there isn't time for thinking, that there are only emergencies to which one must react, that one can't keep up and might as well not try" (Dean 2013:2). Here the pace at which we cannot comprehend what is happening not only kills critical thought, but also drives revenue among a distracted mass of web-surfers who distractedly click their ways through content. For Dean, "communicative capitalism" is the idea that "contemporary communications media capture their users in intensive and extensive networks of enjoyment, production, and surveillance" (Dean 2013:3-4). We enjoy falling down click holes or feel like we're resisting capitalism by posting things on Twitter-often called "slacktivism" (Fuchs 2013).

In the current phase of capitalism, unending consumption characterizes the expansion of the means of consumption. We rarely buy our media and cultural texts, but rather subscribe. This has changed consumers from owners to renters and transformed the fundamental logic of many commodities, especially where it comes to streaming (Arditi 2021). In the Spotify model of retail remuneration to musicians, subscribers pay roughly $\$ 10 / \mathrm{month}$, but their payment goes to the most streamed artists, not necessarily the ones any given user listens to. Furthermore, labels earn money in the aggregate from their artists even when those artists do not receive pay (Arditi 2018). The aggregate benefits felt by labels come from corporate strategies to implement favorable policies. "Even as some media forms eclipse others, global conglomerates profit from the innovations while pernicious arrangements of state power benefit from a diverted populace" (Dean 2013:39). Corporate conglomerates institute changes to the economy that increase profits, while these shifts endanger the livelihoods of people throughout society.

Just as shifts in the consumption side of capitalism occurs periodically, shifts occur on the labor side, too. Today this shift is characterized by precarious employment. Harry Braverman saw a previous "upheaval" in which the majority of the US population transformed from farm work to industrial labor. As recently as the 1960s, "we still thought of the farming population as one of the great classes of modern society. Now, it's a mere remnant of its former self, dominated . . . by great corporate farms and embracing a total workforce that is far exceeded even by the number of college students" (Braverman 1994:19). Braverman's classification of this shift as an "upheaval" is accurate insofar as the shift changed many people's relationship to the means of production. However, we see an equally monumental shift away from industrial labor since the 1970s. Today's shift away from industrial labor is not a shift away from the working class, but rather an ideological shift away from who we view as workers.

If Fordism was characterized by labor stability supported by union power, then unending consumption is characterized by labor precarity and "flexibility." In Karl Marx's critique of capitalism, he asserted the price of labor equaled the average necessary cost to reproduce the worker (Marx 2000). The cost to reproduce the worker included 
the basic and social needs for the worker and the next generation of workers. Alongside, there was an ever-present underclass that was often underemployed and generally outside of the capitalist working class, which did not receive wages that allowed for the reproduction of the class. However, in contemporary capitalism, few jobs pay for the cost of the reproduction of the worker. As people lost their union jobs, they were forced into the secondary labor market, "providing workers with low pay, few benefits, and a level of economic insecurity in which work today doesn't necessarily mean work tomorrow-the very definition of gig employment" (Ravenelle 2019:37). With platforms such as TaskRabbit (Schor 2020), the labor market of flexible precarious workers becomes an on-demand commodity available to complete any task for very low wages. Platform-based companies use "algorithmic exploitation" (Jiménez González 2021) to place the right number of workers to earn revenue at a wage unlikely to benefit the workers themselves. This "platform capitalism" (Srnicek 2017) obscures the position of platforms as employers by making computer platforms appear to provide a service that connects independent contractors to consumers; meanwhile the independent contractors work fulltime for these companies.

Gig workers are set-up as independent contractors and independent contractors are not employees. In the American labor system, employers must pay employees a minimum wage; hourly employees may not work over 40 hours without overtime pay (in most cases); there are specific work conditions mandated by federal and state law; employers above a certain size must pay for their employees' health insurance. However, contract law supersedes labor laws (Arditi 2020:11). As long as people sign contracts that identify themselves as independent contractors, labor law does not apply. Independent contractors are little capitalists (i.e., petite bourgeoisie) or small business owners. These little capitalists now pervade the gig economy. Part of this stems from the logic of neoliberalism where the state subcontracts its functions to private business (Harvey 2005:160). When the state privatizes functions, it does so to avoid paying the more generous benefits and salaries of the state, while private businesses pocket surplus value derived from paying workers less. In the case of private business subcontracting labor as opposed to paying employees and providing them with benefits, it is with the goal of avoiding labor laws entirely. From Uber drivers to freelance journalists and adjunct professors to house cleaners, corporations and state entities use independent contractors to cut labor costs.

Furthermore, contemporary capitalism thrives on a conspicuous consumption in which people live beyond their means through the credit system. Workers do not earn enough to pay for their basic and social needs, but rather pay for these needs within a system of debt. When workers can no longer pay their debts and the economy goes into crisis, governments bail-out the credit providers instead of the debtors as most clearly evidenced by the 2009 Great Recession. Since precarious employees never know when, where, or how much their next paycheck is, they have no option but to live beyond their means. Since they are always on-demand, their labor exists within unending consumption.

\section{Musician Precarity}

Musicians occupy a position in society that seems both superfluous and fundamental to our everyday lives. On the one hand, music does not provide us with a material good that serves our basic needs. On the other hand, would we want to live in a world without music? Since we do not need music to survive, the labor of musicians has often been negated as important; often contemptuously called unproductive labor (a misreading of Marx). People celebrate a handful of musicians while deriding other musicians as needing to get a "real" job. This is the societal love-hate relationship with musicians. However, their position as non-essential (in the COVID-19 parlance) makes us blame musicians for the hardships they face. As such, musicians have long lived under a regime of precarity.

Jacques Attali argues the political economy of the music industry presages the overall organization of the means of production in society (Attali 1985). While Attali emphasized new shifts in musical production in his work, it is just as significant to highlight old forms of organization of the means of production that never changed in the music industry and the way these forms have proliferated in society. For instance, romantic ideals about "the artist" that have existed since the Romantic Era in the 19th century persist throughout the economy writ large (Marshall 2005). In the mythos of entrepreneurialship in makerspaces, the 19th century ideal of artistic and artisanal production that 
correlated with Romanticism becomes reappropriated as opportunity. But Attali's larger point contends we can learn a lot about the political economy of society if we look to music. In this moment, the gig economy, which places the risks of capitalism on the workers (Ravenelle 2019), can be seen in the organization of labor in the music industry since the early 20th century. This is the reality of most musicians and it precedes the move of the economy writ-large to gig work.

From garage bands to pop stars, most musicians are self-employed. Musicians earn money through gigs, sales of recordings and merchandise, and licensing their music and likeness, but they rarely earn a salary. They tend to work as independent contractors regardless of income and/or celebrity status whether they tour, play weddings, record sessions in studios, or sign a record label. "Perhaps more so than any other creative worker, musicians struggle with the possibilities and the perils of freelance labor and technological change. These struggles may be a common feature in the growing gig economy today, but they have long been enduring features of life for music artists" (Watkins 2019:70-71). Being a freelance worker means musicians ostensibly work as their own boss, but it also means the burden to find sources of income remains on the musicians themselves.

When a musician signs a record contract, they sign away their copyrights in exchange for an advance on royalties. That advance needs to be paid back from the musician's royalties before they ever see a dime from the sale of their music. After signing with a label, musicians lose autonomy and they must follow the creative and business suggestions of the label or risk the label's refusal to distribute their music. For all intents and purposes, they work for their record label, but they are not considered workers: they are contractors. Musicians remain independent small businesses who contract with labels to provide a service; they agree to record and sell their music for the label in exchange for an advance on record sales, but record labels do not pay them for their labor. This amounts to a "winner-takes-all culture of creativity centered on the acquisition of intellectual property" (Ross 2008:39). In other words, labels sign musicians to control their copyrights. Under this system, labels do not owe musicians anything as workers. It is up to recording artists to market themselves and generate sales. Many recording artists have described the system as akin to sharecropping (Love 2000; Slichter 2004). Still, musicians desire to sign record contracts, the ideology of getting signed (Arditi 2020), a mechanism used to exploit musicians by acquiring their copyrights.

Since some musicians only see their production as a fun hobby where they do not intend to earn money and any earnings is seen as "extra money" (Naulin and Jourdain 2020:2), musicians who depend on revenue from their music to survive become increasingly exploited. When one person is willing to do something for free, it lowers the money available to everyone. Ioannis Tsioulakis and Ali Fitzgibbon stress "this practice risks normalising the widespread idea that artists are performing a free service to which 'consumers' are entitled" (Tsioulakis and Fitzgibbon 2020). For instance, if a wedding band is just getting started and agrees to play a friend's wedding for free, then it eliminates a gig for an established band and they have to lower their prices as the new band begins undercutting their revenue.

Since there is always an excess of musicians trying to make it in the music industry or play gigs on the local level, musician labor is always a reserve army of labor. When recording music became the dominant aspect of the music industry, it threw a large number of musicians into this reserve army. Before recorded music became the dominant mode of music distribution and consumption, there was heavy demand for musicians everywhere. For instance, when the film industry took off with silent films, they needed musicians to play in pit orchestras across the world. Theaters hired local musicians to perform in these groups to provide auditory stimulation to moviegoers. However, as films became "talkies," there was increased demand to record music for the films in recording studios in Los Angeles. This resulted in a major conflict within the American Federation of Musicians (AFM), the musician's union (Zinn, Kelley, and Frank 2002). Live music performers would not allow studio musicians to join AFM because they viewed studio musicians as a way of undercutting their work through machines - this is similar to the German Luddites resisting machines (Mueller 2021). Over time, the live musicians lost their battle and their jobs. It turns out pit orchestra musicians were right: recorded music means films require fewer musicians.

Over the past century, live music performers have seen an array of entrants into their spheres. Before the advent of the jukebox, bars and restaurants had to have live music for musical entertainment; with the jukebox, fewer 
musicians were necessary to entertain guests. With the popularization of DJs in the disco era, bars could pay less for music than bands and have a more consistent product; whereas a band may need $\$ 100$ per band member, a DJ could earn $\$ 100$ for a night. A similar phenomenon happened for wedding and party gigs where a DJ could be hired for less than a cover band. Now, even DJs are undercut by the ability for people to make their own playlists using Spotify or Apple Music. New technology in the studio also led to more work being done by the producer, eliminating the need for session musicians (Arditi 2014). It is not my place to judge the aesthetic impact of such technological shifts, but rather to demonstrate the shifts impact the labor of musicians.

Because of the low pay and precarious employment situation for musicians, there is a popular trope for them to have a "day job." While these day jobs occur across the labor sector, musicians who identify their primary work as musicians cluster in various service positions. Musicians often work in the service industry because these jobs are flexible and relatively easy to quit if a music gig interferes with their work schedule. Common day jobs for musicians include working in restaurants, teaching music lessons, working at a music retail store, driving for Uber and Lyft, or in any number of gig economy jobs. What we see is that musicians often work in the gig economy because of the flexibility that allows them to play gigs without interfering with work.

While it is fairly easy to book gigs at local venues, it is precisely the low barrier to entry that drives down wages. When disruptions to gigs occur, there is little in the form of a social safety net to catch musicians. Next, I look at the impact of COVID on musicians' lives.

\section{| Musicians During COVID}

A conversation I had with a bass player, Victor, 2 is exemplary of the problems faced by musicians during COVID. At the time we spoke, Victor was 21 and had gigged locally around Dallas for 3 years. In early February 2020, Victor quit his day job as a bartender to prepare for a tour with his up-and-coming band in April 2020. This would be the first time Victor committed himself 100\% to a career in music. Of course, in April the COVID pandemic prompted local officials to close virtually all music venues in the United States for the foreseeable future. "For working musicians who rely primarily on the incomes generated from live performances, sheltering-at-home is not only financially catastrophic, but it also presents a real challenge in thinking about how to interact with their audiences" (Lee and Kao 2021). Even though the Coronavirus Aid, Relief, and Economic Security (CARES) Act, signed into law on March 27, 2020 had relief for gigging musicians, Victor feared that he missed the criteria to qualify. Congress passed the CARES Act as a way to provide welfare for people who lost income as a result of COVID 19, but much of it depended on demonstrating previous income earned. Since Victor never claimed his music earnings on his taxes, he feared that he was ineligible for relief and since he quit his job as a bartender, he did not qualify for unemployment. The precarity of musicians during good times became amplified by the pandemic shutdown of live performance venues. While alternatives and patches were available for performers, the vast majority of musicians had to reconsider their career as or dreams of becoming a professional musician. When a disruption of any sort occurs in a musician's life, it can have the effect of limiting their income and making it difficult for them to meet their needs; COVID created the perfect storm for musicians.

Not having the ability to play shows affects musicians in both the short-term and long-term. Clearly, in the shortterm, many musicians lacked the means to meet their basic needs, but in the long-term their careers could take a hit. It takes time for musicians to build a following, and musicians must constantly sustain their fan base in order to continue their careers. Kagey Parrish of The Honey Dewdrops described it the following way to ABC News:

\footnotetext{
"In fact, we were on tour in California on March 12, 2020, the day the national lockdown was announced and travel bans were issued," Parrish said. "The gig economy fell apart overnight. It took us 11 years to get to that point where we could schedule multiple international tours in a year and continue to build audiences across the U.S. Everything went into limbo pretty quickly. The financial side of things is hard even in normal times" (Haworth 2021).
} 
Parrish and his wife and bandmate Laura Wortman were 3,000 miles from home when the lockdown hit facing an uncertainty about their careers and future. Musicians cannot replace the work they did over 11 years through digital networks. Plenty of musicians I spoke with complained that they cannot take off from touring or they risk losing their fan base. The harm done to touring musicians is incalculable. "One key consideration for artists during the course of the pandemic thus far has been maintaining some sort of relevance" (Frenneaux and Bennett 2021:71). Digital platforms allow for the construction of a virtual scene whereby musicians can maintain connections and try to weather the pandemic. However, the uncertainty of the future of live performance industry does not quell musicians' anxieties or immediate material needs.

Pandemic unemployment for musicians was not limited to independent artists. Some of the best jobs for musicians are in ancillary industries like the cruise industry. Cruise ship musicians work on short-term contracts, usually 3-6 months, but can make a decent living with room and board included (Cashman and Hayward 2020). However, during a crisis like the COVID pandemic, their careers are particularly precarious as the cruise industry has closed for over a year at the time of writing. Other music jobs such as Broadway freelance musicians have enviable gigs compared to other musicians. In a Billboard interview, Meg Toohey, a Broadway guitarist playing for the hit Waitress at the time of the lockdown, described the privilege of being on Broadway as the following:

Broadway is the one gig that musicians look at as a sure [thing] - it's a constant cycling of work, you're in a union. I had great health insurance, I had a regular paycheck that was a great paycheck because of the union, I had vacation days and a $401(\mathrm{k})$. As far as making a living as a musician, that was the way. You can support a family on a Broadway gig (Havens 2020:34).

Toohey's emphasis on the union's role in Broadway being a great gig is noteworthy because she no doubt received support from the union, show, and the CARES Act. However, like Wortman and Parrish, Toohey tried to learn to survive in a digital environment (more below). She sums up the collective experience of Broadway musicians as "So many people I know finally got to that level of, 'I'm making a living as an artist,' and then all of a sudden it's gone. It's all gone" (Havens 2020:34). Each type of musician faced a different set of circumstances when music venues closed, but they all had to figure out ways to earn a living.

Live streaming and social media appeared at first glance to be the solution for musicians to continue performing and distributing music to fans from home. "Live streaming refers to audio and visual information that is transmitted over the Internet and received simultaneously" (Zhang and Negus 2021). The techno-utopian impulse that the Internet will save everyone became the dominant perspective from the outset of the lockdown across the economy. While many people across the world became conversant in Zoom and Microsoft Teams meeting platforms, musicians devised ways to live stream their music to fans. My point is not to question the aesthetic or cultural value of these platforms, something others are wrestling with (Hanrahan 2018, 2019; Hesmondhalgh 2021), but rather to draw attention to the inequity in their uses. As mentioned above, The Honey Dewdrops tried to maintain their connection with fans by learning to use streaming. Some musicians went to social media platforms (Instagram Live, Facebook Live, Twitter Live), other went with mainstream streaming platforms (Twitch and YouTube), but many found ways to live stream concerts using new streaming start-ups specifically designed for live music performances. And many musicians streamed their performances free of charge (Tsioulakis and Fitzgibbon 2020). These platforms enabled what James Rendell labels "portal shows" - shows "that are both live music events and screen media texts, where the portalisation of shows are performed live to predominantly, if not entirely, online audiences across a digital threshold" (Rendell 2020:6). These portal shows became the dominant way to experience simultaneous music performance. In 2021 "livestreaming transformed from a niche business to an essential, eight-figure industry amid the coronavirus pandemic, spurring the launch of over a dozen new platforms in a market that now looks pretty crowded" (Cirisano 2021:21). However, the live streaming infrastructure developed primarily for established artists to engage fans, often leaving behind the majority of precariously situated musicians.

Live stream platform startups saw an overnight boom when the live performance industry shuttered from the COVID pandemic. This made them valuable businesses for live music companies like Live Nation to purchase. Live 
Nation sees the future as a hybrid where venues stream live performances to people who for one reason or another do not want to attend in-person. Live Nation buttressed this approach by purchasing Veeps an established platform that launched in 2017 (Millman 2021). After the acquisition of Veeps, Live Nation's stock hit "a new all-time high of $\$ 77.02$ per share, even though the company's revenue has dropped to about $5 \%$ of its prepandemic intake" (Cirisano 2021:22). Other novelties the live music industry hopes to cash-in on include Mandolin Parties, which allows fans to host live streaming parties at their homes (Cirisano 2021). Mandolin Parties present a concert-in-a-box with access to the platform, food, drinks, and merchandise available at your home. The aim of these new live stream events is to create a "sharing" platform through which people can host live streamed events at houses or venues the same way Airbnb or Uber shift the costs onto gig workers at the same time cutting the money paid to performers. In the era of unending consumption, businesses explore ways to commodify everything, but this has the tendency to hurt gig workers more than other forms. Imagine a musician coming to set-up a Mandolin Party with a special sound system, food, drinks, and your pre-ordered merchandise. This musician would earn a low wage for setting up and tearing down the party, but would have earned more if people would have attended their show instead. New corporate live streaming platforms present opportunities to generate more surplus value from fewer shows.

While streaming technology is widely available, gaps remain between independent artists and pop stars and they only expanded during the COVID shutdown. The marginalization of groups and the gaps between rich and poor expanded as a result of access to networks willing to stream. Toohey states, "Everything musical went to social media. So on top of this game of, "Can you get your song on a TikTok?," every five minutes somebody enormous is doing the same thing you used to do on Instagram where people might actually watch. Now, all of a sudden, you go live and Miley Cyrus is on with Kamala Harris. With the oversaturation in media, it's kind of impossible to compete" (Havens 2020:34). While megastars played shows on television from their homes, lesser-known musicians struggled to get fans, friends, and family to tune-in to live streams. Disney produced two Disney Singalongs that featured stars from Donald Glover to Arianna Grande and Michael Bublé to John Legend. Trisha Yearwood and Garth Brooks hosted a television special from their home studio on CBS. There was even a charity event for the World Health Organization to celebrate frontline health workers, entitled One World: Together at Home; despite its altruistic goals it helped increase streams for established celebrities (McIntosh 2021). Billboard kept a running list of these television specials and live streams, but the limited list emphasized music stars (Staff 2021). But each live stream show lacks exclusivity, there is nothing to distinguish one show from the next. If a band performs in Geneva, Switzerland, only people in and around Geneva can see the performance. A tour inspires fans to go out and see a band when they visit a city, but a Tuesday night live stream does not differentiate from a Wednesday night show. While streaming platforms can earn a great deal of revenue on the aggregate from any performances, most gigging musicians struggle to make money. Furthermore, the biggest acts in music support large crews. These crew members, from touring musicians to bus drivers, depend on touring to earn income. With two seasons of tour interruptions, the rescheduled shows are turning to canceled shows forcing crew members to find new careers (Edgers 2021). Streaming and televised shows do little to change the dynamics of gig work.

For major record labels, live streaming represents a long-term opportunity to increase consumption. "What started as mostly free virtual bedroom performances early on in the touring shutdown have evolved into costly, ticketed productions that keep growing bigger and bolder" (Cirisano 2021:21). Where concerts were limited to specific places, major music corporations see live streaming as a way to bring concerts everywhere. The problem in this description lies in the inequity between those who benefit from live streaming and those who suffer from it. At the heart of almost every news article I read about the hardships musicians faced during the pandemic was a silver lining: musicians could live stream their music to fans. The reporters always interviewed popular musicians who found success in the medium. Rarely did these reporters discuss the widespread failures of live streaming. Few people really want to watch a live streamed performance. At first it felt like something novel that could deliver us from our boredom, but quickly we realized it is not the same thing as going to a show. It lacks the collective effervescence that brings together people through cultural practice (Durkheim 2008). When we attend concerts, collective effervescence is the feeling you gain from being around other people when the experience feels great. The feeling is not the same watching performances on a computer or television screen. Bandsintown's data demonstrates the lackluster reception of live streaming as the website went from a pandemic high of "2,700 concerts per week in May [2020] to under 900" 
by January 2021 (Cirisano 2021:22). However, big business sees big money beyond the novelty. Super fans of superstar musicians will pay for the experience and others will continue to pay to say they were part of something. But this does not translate to the local and independent music scenes. Live streaming recreates the inequality in the music industry.

The federal response to coronavirus demonstrates the power of big businesses to receive support while gigging musicians suffered from the shutdown. Independent music venues banded together to create the National Independent Venue Association (NIVA) early during the pandemic (Brooks 2021). The result of this newly-founded trade organization was the Save Our Stages Act. Championed by Senators Amy Klobuchar (D-Minnesota) and John Cornyn (R-Texas), the Act aimed to provide much needed relief to independent venues shuttered during the COVID crisis. They argued that music venues would be the "first to close, last to reopen" (Brooks 2021:32). Since many Americans love live music, this was an easy sell and it ultimately became a part of the December 27, 2020 COVID relief package-garnering $\$ 15$ billion for live music venues, zoos, and museums. This was crucial money for these (mostly) small businesses - it is important to note that while many independent venues are small, some are in fact very large. However, there was no parallel effort for independent musicians. Yes, musicians play at venues, but there is no mechanism for this money to "trickle down" to musicians. The argument for the venues is that venues will need to be around after the pandemic for musicians to perform, but what do musicians do as they await the reopening of music venues? When the petite bourgeoisie start their businesses, isn't this the risk they take in capitalism? Why should the state look out for businesses, but not workers? This model of capitalism places all risk on the most vulnerable people: the workers.

As I discussed earlier, the precarity and inconsistency of paying gigs for musicians leads them to have a day job or a side-gig. However, jobs across the gig economy dried up with the COVID lockdown. Since musicians fill other gig roles, COVID killed musicians' side-hustle, amplifying their problems. Musicians embody the hustle, which Craig Watkins defines as "an improvisational and creative assertion of agency in the face of uncertain circumstances" (Watkins 2019:11). In Alexandrea Ravenelle's terms, people hustle to become "success stories," but more often than not they are "strugglers" (Ravenelle 2019:10-11). One way musicians hustle is by working multiple gig jobs-what is known as portfolio work (Tsioulakis and Fitzgibbon 2020). Musicians often supplement their income with flexible employment in the food industry. They work as bartenders, servers, or line-cooks in restaurants where they can easily take a night off for a gig. Or they work in the so-called gig economy as drivers, deliverers, or doing odd-jobs. In my research, I came across multiple Uber drivers who were musicians or musicians who discussed driving for Uber or Lyft. When COVID-19 decimated live music performance it also crushed these side-hustles. "As a result, the multiple income streams on which performing artists rely have all disappeared" (Tsioulakis and Fitzgibbon 2020). Juliet Schor discusses the way many gig workers don't think of their work as their main job, and instead view it as their side-gig (Schor 2020). The problem is that many of these workers are also precariously employed in their main work. A theme I noticed in my research is many musicians drive Uber and Lyft when they are not playing music. They view driving for a rideshare company as the side-gig, but it is no less precarious than their main job as a musician (and it often provides more income). But with the COVID lockdowns, Uber drivers had a difficult time finding riders because people stopped leaving their homes. A musician who drives Uber or worked part-time at a bar, no longer had their side-hustle, either. The COVID lockdown harmed gig work for musicians across the gig economy.

\section{Conclusion}

We will not know the full impact of COVID on musicians. It is doubtless that while many musicians canceled tours, many also stopped playing music altogether. Rhetoric about struggling artists only goes so far. At the same time, businesses developed new ways to profit from the lockdown as live streaming platforms convinced many musicians that live streaming would solve all of their problems.

The key point is the problems faced by musicians during COVID cannot be separated from the moment of capitalism. Precarity leads gig workers to find alternatives. Capital offers solutions to these workers by selling them false hope, but the false hope is another form of profit generation through exploitation of workers. Musicians, like all other gig workers, live through precarious employment situations. Furthermore, many musicians have other gig jobs 
like driving for Uber or working as restaurant servers, making them that much more vulnerable to the problems of the lockdown. The system must change and the effects of the COVID lockdown are merely a symptom of the current era of capitalism. 


\section{Endnotes}

1. Other studies have tried to quantify the harm. According to a study by Michael Seman and Richard Florida, musicians were hit especially hard by the pandemic. From April 1 through July 31, 2020, they "estimate losses of 2.7 million jobs and more than $\$ 150$ billion in sales of goods and services for creative industries nationwide, representing nearly a third of all jobs in those industries and 9\% of annual sales"
(Seman and Florida 2020). These heavy losses are only for a 4-month period-unfortunately, the stoppages for music performance continue 18 months into the pandemic. During the period, Seman and Florida estimated 253,349 musicians (or 10.9\%) lost their jobs (Seman and Florida 2020).

2. All names in this essay are pseudonyms. .

\section{Bibliography}

Agger, Ben. 1988. Fast Capitalism. Urbana, IL: University of Illinois Press.

Agger, Ben. 2004. Speeding Up Fast Capitalism: Cultures, Jobs, Families, Schools, Bodies. Boulder, Colo: Routledge.

Aglietta, Michel. 2001. A Theory of Capitalist Regulation: The US Experience. New Edition edition. New York, NY: Verso.

Antonio, Robert J. 1981. "Immanent Critique as the Core of Critical Theory: Its Origins and Developments in Hegel, Marx and Contemporary Thought." The British Journal of Sociology 32(3):330-45.

Arditi, David. 2014. "Digital Downsizing: The Effects of Digital Music Production on Labor." Journal of Popular Music Studies 26(4):503-20.

Arditi, David. 2018. "Digital Subscriptions: The Unending Consumption of Music in the Digital Era." Popular Music and Society 41(3):302-18. doi: 10.1080/03007766.2016.1264101.

Arditi, David. 2020. Getting Signed: Record Contracts, Musicians, and Power in Society. New York, N.Y: Palgrave Macmillan.

Arditi, David. 2021. Streaming Culture: Subscription Platforms and the Unending Consumption of Culture. New Milford, CT: Emerald Publishing Limited.

Attali, Jacques. 1985. Noise: The Political Economy of Music. Minneapolis: University of Minnesota Press.
Braverman, Harry. 1994. "The Making of the U.S. Working Class." Monthly Review 14-35. doi: 10.14452/MR-046-06-1994-10_2.

Braverman, Harry. 1998. Labor and Monopoly Capital: The Degradation of Work in the Twentieth Century. New York: Monthly Review Press.

Brooks, Dave. 2020. "The Year That Broke the Business." Billboard, December 19, 98-103.

Brooks, Dave. 2021. "From the Desk of Dayna Frank." Billboard, January 16, 30-32.

Cashman, David, and Philip Hayward. 2020. Cruisicology: The Music Culture of Cruise Ships. Lanham, MD: Lexington Books.

Cirisano, Tatiana. 2021. "The Next Stage.” Billboard, January 30, 21-22.

Dean, Jodi. 2013. Blog Theory: Feedback and Capture in the Circuits of Drive. 1 edition. Polity.

Durkheim, Emile. 2008. The Elementary Forms of Religious Life. 1 edition. edited by M. S. Cladis. Oxford: Oxford University Press.

Edgers, Geoff. 2021. "For Performers Trying to Get Back Onstage, It's Been a Struggle to Balance Covid Safety and the Show." Washington Post, October 9.

Frenneaux, Richard, and Andy Bennett. 2021. "A New Paradigm of Engagement for the Socially Distanced 
Artist.” Rock Music Studies 8(1):65-75. doi: 10.1080/19401159.2020.1852770.

Fuchs, Christian. 2013. Social Media: A Critical Introduction. Thousand Oaks, CA: SAGE Publications Ltd.

Gottfried, Heidi. 1995. "Developing Neo-Fordism: A Comparative Perspective." Critical Sociology 21(3):39-70. doi: 10.1177/089692059502100302.

Hanrahan, Nancy Weiss. 2018. "Hearing the Contradictions: Aesthetic Experience, Music and Digitization." Cultural Sociology 12(3):289-302. doi: 10.1177/1749975518776517.

Hanrahan, Nancy Weiss. 2019. "Digitized Music and the Aesthetic Experience of Difference.” Pp. 165-79 in The Dialectic of Digital Culture, edited by D. Arditi and J. Miller. Lanham, MD: Lexington Books.

Harvey, David. 2005. A Brief History of Neoliberalism. Oxford ; New York: Oxford University Press.

Havens, Lyndsey. 2020. “Second Acts: Broadway's Freelance Musicians Are Facing Their Own Set of Struggles." Billboard, November 14, 34.

Haworth, Jon. 2021. "For Musicians and Artists, COVID-19 Pandemic Was a Turning Point." ABC News, February 14, Online.

Hesmondhalgh, David. 2021. "Streaming's Effects on Music Culture: Old Anxieties and New Simplifications." Cultural Sociology 17499755211019974 . doi: $10.1177 / 17499755211019974$.

Jiménez González, Aitor. 2021. "Law, Code and Exploitation: How Corporations Regulate the Working Conditions of the Digital Proletariat." Critical Sociology 08969205211028964 . doi: $10.1177 / 08969205211028964$.

Lee, Wonseok, and Grace Kao. 2021. “'You Know You're Missing Out on Something': Collective Nostalgia and Community in Tim's Twitter Listening Party during COVID-19.” Rock Music Studies 8(1):36-52. doi: 10.1080/19401159.2020.1852772.
Love, Courtney. 2000. "Courtney Love Does the Math." Salon, June 14, Online.

Marshall, Lee. 2005. Bootlegging: Romanticism and Copyright in the Music Industry. 1st ed. California: SAGE Publications Ltd.

Marx, Karl. 2000. “Wage-Labour and Capital.” Pp. xi, 687 p. in Selected Writings. Vol. 2nd, edited by D. McLellan. Oxford ; New York: Oxford University Press.

McIntosh, Heather. 2021. "Charity Benefit Concerts and the One World: Together at Home Event." Rock Music Studies 8(1):76-82. doi: 10.1080/19401159.2020.1852773.

Millman, Ethan. 2021. “Live Nation Buys Veeps, Joel and Benji Madden's Livestreaming Company." Rolling Stone. Retrieved June 14, 2021 (https://www.rollingstone.com/pro/news/live-nation-veeps-joel-madden-livestreaming-1116039/).

Mueller, Gavin. 2021. Breaking Things at Work: The Luddites Are Right About Why You Hate Your Job. Verso Books.

Naulin, Sidonie, and Anne Jourdain. 2020. "Introduction: The Marketization of Everyday Life." Pp. 1-30 in The Social Meaning of Extra Money: Capitalism and the Commodification of Domestic and Leisure Activities, Dynamics of Virtual Work, edited by S. Naulin and A. Jourdain. Palgrave Macmillan.

Ravenelle, Alexandrea. 2019. Hustle and Gig: Struggling and Surviving in the Sharing Economy. First edition. Oakland, California: University of California Press.

Rendell, James. 2020. “Staying in, Rocking out: Online Live Music Portal Shows during the Coronavirus Pandemic." Convergence 1354856520976451. doi: $10.1177 / 1354856520976451$.

Ross, Andrew. 2008. “The New Geography of Work: Power to the Precarious?" Theory, Culture \& Society 25(7-8):31-49.

Schor, Juliet B. 2020. After the Gig: How the Sharing Economy Got Hijacked and How to Win It Back. First edition. Oakland, California: University of California Press. 
Seman, Michael, and Richard Florida. 2020. Lost Art: Measuring COVID-19's Devastating Impact on America's Creative Economy. Metropolitan Policy Program at Brookings.

Slichter, Jacob. 2004. So You Wanna Be a Rock \& Roll Star: How I Machine-Gunned a Roomful of Record Executives and Other True Tales from a Drummer's Life. New York: Broadway Books.

Smith, Paul. 1997. Millennial Dreams: Contemporary Culture and Capital in the North. London ; New York: Verso.

Srnicek, Nick. 2017. Platform Capitalism. Cambridge, England; Malden, Massachusetts : Polity.

Staff. 2021. "Here Are All the Livestreams \& Virtual Concerts to Watch During Coronavirus Crisis." Billboard, January 26.

Tsioulakis, Ioannis, and Ali Fitzgibbon. 2020. Performing Artists in the Age of COVID-19. Queen's Policy Engagement. Belfast, Ireland, UK: Queen's University Belfast.

Watkins, S. Craig. 2019. Don't Knock the Hustle: Young Creatives, Tech Ingenuity, and the Making of a New Innovation Economy. Beacon Press.

Woodcock, Jamie, and Mark Graham. 2020. The Gig Economy: A Critical Introduction. 1st edition. Cambridge ; Medford, MA: Polity.

Zhang, Qian, and Keith Negus. 2021. "Stages, Platforms, Streams: The Economies and Industries of Live Music after Digitalization.” Popular Music and Society 0(0):1-19. doi: 10.1080/03007766.2021.1921909.

Zinn, Howard, Robin D. G. Kelley, and Dana Frank. 2002. Three Strikes: Miners, Musicians, Salesgirls, and the Fighting Spirit of Labor's Last Century. Boston: Beacon Press. 